\title{
ANALISIS KETERAMPILAN MENGAJAR GURU DAN PENANAMAN NILAI POSITIF MELALUI PEMANFAATAN KEBUN SEKOLAH
}

\author{
Salati Asmahasanah \\ Maemunah Sa'diyah \\ Ibdalsyah \\ Universitas Ibn Khaldun Bogor \\ Jln. KH Sholeh Iskandar Km 2 Kota Bogor, Jawa Barat \\ e-mail: salati@fai.uika-bogor.ac.id
}

\begin{abstract}
The purpose of this study is to describe the use of the environment as a medium that can improve teacher competence in teaching and develop creativity and independence of teachers in managing learning. This study uses qualitative descriptive method. Data collection is done through interviews, observation, and documentation studies. The object of this research is the teacher and student partner school consisting of four MIS at the foot of Mount Salak, Taman Sari District, Bogor. The results of the study show the role of universities in pedagogical improvement and teacher learning planning, school communication media as learning media can increase positive values, naturalistic intelligence, and student entrepreneurial skills by further improving the environment.
\end{abstract}

Keywords: higher education, pedagogical competence, school garden

\begin{abstract}
Abstrak: Tujuan penelitian ini untuk mendeskripsikan pemanfaatan lingkungan alam sebagai media yang dapat meningkatkan kompetensi guru dalam mengajar serta mengembangkan kreativitas dan kemandirian guru dalam mengelola pembelajaran. Penelitian ini menggunakan pendekatan kualitatif dengan metode deskriptif. Pengumpulan data dilakukan melalui wawancara, observasi, dan studi dokumentasi. Objek penelitian ini adalah guru dan siswa sekolah mitra yang terdiri dari empat MIS di kaki Gunung Salak Kecamatan Taman Sari Kabupaten Bogor. Hasil penelitian menunjukkan adanya peran perguruan tinggi dalam peningkatan pedagogik dan perencanaan pembelajaran guru, pemanfaatan kebun sekolah sebagai media pembelajaran dapat meningkatkan nilai positif, kecerdasan naturalistik, dan keterampilan entrepreneur siswa dengan lebih menghargai lingkungan.
\end{abstract}

Kata kunci: perguruan tinggi, komptensi pedagogik, kebun sekolah

Pendidikan menjadi tumpuan upaya pemerintah untuk mendorong pencapaian tujuan dan sasaran pembangunan berkelanjutan dalam era Sustainable Development Goals (SDGs). Hal ini berlaku hingga tahun 2030 berdasarkan arahan dari Forum PBB yang telah disepakati pada tanggal 2 Agustus 2015. Peningkatan pendidikan bagi masyarakat Indonesia akan mendorong pencapaian tujuan dan sasaran lainnya dalam 17 poin SDGs. Poin tersebut khususnya untuk meningkatkan indeks pembangunan manusia Indonesia sehingga peran pendidikan diharapkan mampu meningkatkan daya saing Indonesia dalam mendukung SDGs 2030.

Salah satu upaya yang dilakukan dalam meningkatkan kualitas pendidikan adalah memperbaharui proses pembelajaran menjadi lebih baik 
dan bermutu sesuai dengan tujuan pendidikan nasional. Sebagaimana dirumusan tujuan pendidikan yang terdapat dalam pasal 3 Undang-Undang No. 20 tahun 2003 tentang sistem pendidikan nasional bahwa "pendidikan nasional berfungsi mengembangkan kemampuan dan membentuk watak serta peradaban bangsa yang bermartabat dalam rangka mencerdaskan kehidupan bangsa, bertujuan untuk berkembangnya potensi peserta didik agar menjadi manusia yang beriman dan bertakwa kepada Tuhan Yang Maha Esa, berakhlak mulai, sehat, berilmu, cakap, kreatif, mandiri dan menjadi warga negara yang demokratis serta bertanggung jawab".

Berkaitan dengan peningkatan kualitas pendidikan, maka guru selaku aktor utama pelaksana proses pembelajaran hendaknya mendapat perhatian utama. Guru sebagai pendidik yang berkualitas juga akan mendorong siswa yang berkualitas. Guru harus memiliki kompetensi dalam melaksanakan profesinya, sebagaimana dijelaskan dalam UU Nomor 14 tahun 2005 tentang guru dan dosen, pasal 10 ayat (1). Pada UU tersebut dinyatakan "kompetensi guru sebagaimana dimaksud dalam pasal 8 meliputi kompetensi pedagogik, kompetensi kepribadian, kompetensi sosial dan kompetensi professional yang diperoleh melalui pendidikan profesi". Kompetensi pedagogik inilah yang menjadi modal utama bagi guru dalam mencapai tujuan pendidikan yang bermutu.

Kehandalan kemampuan guru dalam mengajar dan mendidik dibidangnya akan memaksimalkan ketercapaian target dan sasaran pendidikan di sekolah. Pendapat Sadulloh (2007) menyatakan bahwa pedagogik ini merupakan ilmu yang membahas pendidikan, yaitu ilmu pendidikan siswa. Jadi, pedagogik mencoba menjelaskan tentang seluk beluk pendidikan siswa sehingga dikaji tentang bagaimana membimbing anak, bagaimana sebaiknya pendidikan berhadapan dengan siswa, apa tugas pendidik dalam mendidik anak, apa yang menjadi tujuan mendidik anak. Terdapat beberapa Indikator Kompetensi Guru. Menurut peraturan pemerintah Nomor 19 tahun 2005 tentang standar pendidikan nasional bahwa tenaga kependidikan harus menguasai standar kompetensi pedagogik. Kompetensi pedagogik ini meliputi (1) pemahaman guru terhadap peserta didik; (2) perancangan dan pelaksanaan pembelajaran; (3) evaluasi hasil belajar, dan (4) pengembangan peserta didik untuk mengaktualisasi berbagai potensi yang dimilikinya.
Peningkatan kompetensi guru merupakan salah satu upaya yang dapat dilakukan adalah melalui peran aktif perguruan tinggi dalam melaksanakan pembinaan bagi guru. Hal ini merupakan bagian dari Tri Dharma Perguruan Tinggi yang meliputi kegiatan pendidikan, pengabdian, dan penelitian. Dari kajian hasil penelitian Nuryanto (2017) menyatakan bahwa tugas pendidikan tinggi adalah membantu memberikan suatu pencerahan bagi civitas akademika dan kalangan masyarakat. Oleh karena itu, pendidikan tinggi harus menjadi rasionalitas dikalangan masyarakat sehingga budaya akademik kampus akan terjalin sesuai yang diharapkan. Perguruan tinggi terutama jurusan kependidikan dapat mengambil peran sebagai fasilitator dengan mengadakan workshop atau pelatihan guna mengembangkan kompetensi guru-guru.

Pembinaan yang dilakukan perguruan tinggi untuk meningkatkan kompetensi pedagogik guru melalui pembelajaran berbasis kebun sekolah adalah suatu upaya inovatif dalam pembelajaran. Kebun sekolah merupakan model pembelajaran berbasis alam ini sebenarnya selaras dengan program education for Sustaianble Development (ESD) dari UNESCO yang diterbitkan sejak tahun 2005. ESD terdiri atas tiga pilar yaitu lingkungan, budaya dan ekonomi (Siraj-Baltchford, Smith, \& Samuelsson, 2010). ESD lingkungan salah satunya berkaitan dengan keberlanjutan konsumsi dan produksi. Tujuan pemanfaatan lingkungan alam menjadi media pembelajaran dapat meningkatkan kompetensi mengajar atau pedagogik guru melalui kegiatan pembelajaran kebun sekolah.

Pembinaan yang dilakukan perguruan tinggi untuk meningkatkan kompetensi pedagogik guru melalui pembelajaran berbasis kebun sekolah adalah suatu upaya inovatif dalam pembelajaran. Kebun sekolah merupakan model pembelajaran berbasis alam ini sebenarnya selaras dengan program education for Sustaianble Development (ESD) dari UNESCO yang di launching sejak tahun 2005. ESD (Siraj-Baltchford, Smith, \& Samuelsson, 2010) menyebutkan ESD terdiri dari tiga pilar yaitu lingkungan, budaya dan ekonomi. ESD lingkungan salah satunya berkaitan dengan keberlanjutan konsumsi dan produksi. Tujuan pemanfaatan lingkungan alam menjadi media pembelajaran dapat meningkatkan kompetensi mengajar atau pedagogik guru melalui kegiatan pembelajaran kebun sekolah. 
Melalui pemanfaatan kebun sekolah, siswa diharapkan lebih memahami tentang asal usul makanan dan pola yang lebih sehat. Beberapa penelitian lain juga telah menunjukkan bahwa pemanfataan kebun sekolah mampu memberikan pengaruh terhadap pola makan siswa dan keluarganya. Para orangtua menyatakan bahwa siswa banyak makan buah dan sayur-sayuran, serta memiliki keinginan untuk selalu makan sayur dan buah di rumah (Wayan, 2018). Pemanfaatan kebun sekolah juga dapat meningkatkan kecerdasan natural ssiwa yaitu dalam mengeksplorasi diri dan belajar dari lingkungan alami. Demikian juga hasil penelitian Marheni (2017) yang menunjukkan bahwa pemanfaatan kebun sekolah membuat pembelajaran lebih bermakna karena siswa dilibatkan secara langsung. Siswa dapat mengkontruksi pengetahuannya sendiri dengan memanfaatkan kebun sekolah sebagai laboratorium alami. Berdasarkan hal tersebut maka dalam penelitian ini akan dianalisis peningkatan keterampilan mengajar guru dan penanaman nilai karakter siswa melalui pemanfaatan kebun sekolah.

\section{METODE}

Penelitian ini menggunakan penelitian kualitatif dengan metode dekriptif. Penelitian kualitatif adalah suatu penelitian yang ditujukan untuk mendeskripsikan dan menganalisis fenomena, peristiwa, aktivitas sosial, sikap, kepercayaan, persepsi, pemikiran secara individual maupun kelompok (Sukmadinata, 2010: 60). Pengumpulan data dalam penelitian ini dilakukan melalui pedoman wawancara, pedoman observasi, dan pedoman studi dokumentasi yang telah disusun dan dikembangkan. Adapun objek dalam penelitian ini adalah guru dan siswa sekolah mitra yaitu Madrasah Ibtidaiyah Swasta (MIS) yang berada di daerah kabupaten yang jarang tersentuh perhatian pemerintah di kawasan kaki Gunung Salak Kecamatan Taman Sari Kabupaten Bogor yang dilaksanakan sejak bulan Mei sampai dengan Agustus 2018.

Prosedur analisis data yang digunakan adalah analisis dari Milles dan Huberman (dalam Sangit, 2011) yang mengemukakan bahwa pendekatan dalam analisis data kualitatif terdiri dari reduksi data, penyajian data, pengambilan kesimpulan, dan verifikasi. Analisis data dilakukan dalam bentuk interaktif dengan proses pengumpulan data sebagai suatu proses yang berlanjut, berulang, dan terus menerus hingga membentuk suatu siklus (Sugiyono,
2007:43). Berikut skema dalam prosedur analisis data penelitian ini.

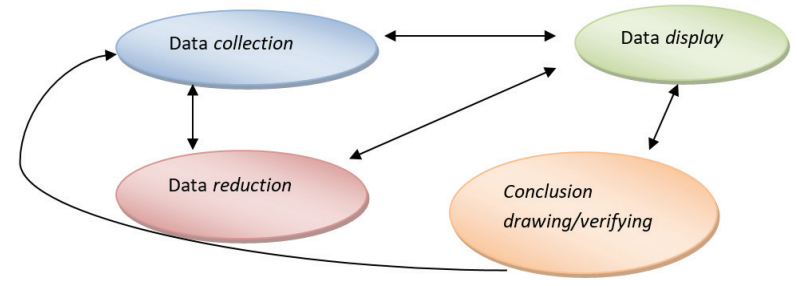

\section{Gambar 1. Prosedur Analisis Data Kualitatif} Sumber: Miles and Huberman

\section{HASIL \\ MIS Alhidayah}

Keadaan kebun sekolah MIS Alhidayah sudah mulai proses pembenihan ulang dan beberapa bagian media terdapat tanaman yang mulai tumbuh dan berkembang seperti bayam dan kankung pada media tanam sedangkan di kotak hijau terdapat daun bawang dan pembenihan cabe dan terong. Media tanal yang tidak tumbuh serempak diakibatkan kurangnya perawatan pada saat liburan semester dan kebun sekolah terbengkalai sehingga bibit yang sudah ditanam gagal berkembang dengan baik selain itu terdapat gangguan hama dan siswa yang mencabut tanaman. Bibit yang ditanam adalah bayam, kankung, daun bawang, causin dan cabe. Pada pengembangan kebun sekolah, tim memberikan tambahan pupuk kompos, $h c l$, bibit cabe, causin dan kankung serta alat berupa arit dan cangkul mini sesuai permintaan sekolah. Guru menambahkan media tanam dengan memanfaatkan botol bekas dan polybag.

Hasil penilaian sikap siswa pada saat proses pembelajaran kebun sekolah yakni: 1) mulai terlihat, adalah sikap menghargai, bertanggung jawab, disiplin, kerjasama, mensyukuri nikmat Allah, dan kepedulian. 2) mulai berkembang, adalah sikap cinta tanaman dan lingkungan, kesabaran, berjiwa sosial, dan semangat entrepreneur. Berikut tahapan proses pembelajaran yang dilaksanakan guru selama proses pembelajaran.

\section{Tabel 1. Tahapan Pembelajaran MIS Alhidayah}

\begin{tabular}{ll}
\hline No & \multicolumn{1}{c}{ MIS Alhidayah } \\
\hline 1. & $\begin{array}{l}\text { Menuliskan contoh kewajiban terhadap } \\
\text { tumbuhan }\end{array}$ \\
2. & $\begin{array}{l}\text { Menjelaskan tahapan-tahapan atau langkah } \\
\text { kegiatan }\end{array}$
\end{tabular}




\begin{tabular}{ll}
\hline No & \multicolumn{1}{c}{ MIS Alhidayah } \\
\hline 3. & $\begin{array}{l}\text { Menjelaskan tentang cinta tanaman dan } \\
\text { lingkungan }\end{array}$ \\
4. & Membawa anak ketempat berkebun \\
5. & $\begin{array}{l}\text { Membuat kelompok untuk bergantian merawat } \\
\text { tanaman kebun sekolah }\end{array}$ \\
\hline
\end{tabular}

\section{MIS Nurul Iman}

Pemanfaatan kebun sekolah MIS Nurul Iman terlihat pada media tanam terdapat sayuran kankung yang sedang tumbuh berkembang sedangkan cauisin sebagian sudah dipanen namun sebagian lagi masih tumbuh. Guru bersama siswa menambah media tanam dengan memanfaatkan ember bekas, paralon bekas dan lahan gundukan tanah dengan ditan MIS Mathla'ul Anwar terlihat tertata rapi namun belum ada yang tumbuh dikarenakan guru dan siswa beberapa hari lalu baru saja bergotong royong menanam ulang karena tanaman yang lama tumbuh kembang kurang bagus dikarenakan faktor hama, kekeringan dan kurang terawat saat libur semester. Sayur yang ditanam adalah kankung, bayam, terong, cauisin, dan cabe. Guru bergotong royong bersama siswa menambah media tanam dengan menggunakan lahan kosong belakang sekolah, membuat gundukan tanah dan dipagari dengan batang singkong.

Hasil penilaian sikap siswa pada saat proses pembelajaran kebun sekolah yakni: 1) mulai terlihat, adalah sikap mensyukuri nikmat Allah, kesabaran dan semangat entrepreneur. 2) mulai berkembang, adalah sikap bertanggung jawab, disiplin, kerjasama, sikap cinta tanaman dan lingkungan, kesbaran, berjiwa sosial, dan kepedulian. 3) membudaya, adalah sikap saling menghargai. Berikut tahapan proses pembelajaran yang dilaksanakan guru selama proses pembelajaran.

\section{Tabel 2. Tahapan Pembelajaran MIS Nurul} Iman

\begin{tabular}{|c|c|}
\hline No & MIS Nurul Iman \\
\hline 1. & $\begin{array}{l}\text { Guru mengucapkan salam dan menanyakan } \\
\text { kabar siswa kemudian berdoa }\end{array}$ \\
\hline 2. & $\begin{array}{l}\text { Guru menyampaikan tema dan tujuan pembe- } \\
\text { lajaran }\end{array}$ \\
\hline 3. & $\begin{array}{l}\text { Guru membentuk kelompok kemudian menga- } \\
\text { jak siswa mengamati kebun sekolah }\end{array}$ \\
\hline 4. & $\begin{array}{l}\text { Guru menjelaskan jenis-jenis alat dan bahan } \\
\text { untuk berkebun }\end{array}$ \\
\hline
\end{tabular}

\begin{tabular}{cl}
\hline No & \multicolumn{1}{c}{ MIS Nurul Iman } \\
\hline 5. & Guru menugaskan siswa menanam sayuran \\
& secara berkelompok \\
6. & Evaluasi dengan memberikan LKS dan soal \\
7. & Penutup \\
\hline
\end{tabular}

\section{MIS Mathlaul Anwar}

Pada pelaksanaan praktek menanam kebun sekolah, sekolah memulai penanaman bibit tanaman kebun sekolah di tempat penanaman yang sudah disediakan oleh TIM UIKA. Guru dan siswa sangat antusias sekali untuk memulainya. Guru dan siswa saling kerjasama dalam melakukan penanaman bibit kebun sekolah. Siswa diberi jadwal bergantian untuk menjaga tanaman, terutama dalam waktu menyiram tanaman. Lahan yang biasanya dijadikan tempat buang sampah dan tidak terurus, sekarang sudah menjadi lahan kebun sekolah untuk siswa.

Hasil penilaian sikap siswa pada saat proses pembelajaran kebun sekolah yakni: 1) mulai terlihat, adalah sikap menghargai, cinta tanaman dan lingkungan, kesabaran, kepedulian, kesabaran dan semangat entrepreneur. 2) mulai berkembang, adalah sikap bertanggung jawab, disiplin, kerjasama, mensyukuri nikmat Allah, berjiwa sosial. Berikut tahapan proses pembelajaran yang dilaksanakan guru selama proses pembelajaran.

\section{Tabel 3. Tahapan Pembelajaran MIS Mathlaul} Anwar

\begin{tabular}{cl}
\hline No & \multicolumn{1}{c}{ MIS Mathlaul Anwar } \\
\hline 1. & Guru memberikan salam dan mengajak berdoa \\
Guru mengecek absensi dan kehadiran siswa & $\begin{array}{l}\text { kemudian menginformasikan tema yang akan } \\
\text { dipelajari }\end{array}$ \\
Guru bertanya jawab dengan siswa tentang tema \\
3. \\
yang dipelajari yaitu peduli terhadap makhluk \\
Guru mengajak siswa ke luar kelas untuk \\
4. $\begin{array}{l}\text { mengamati kebun sekolah dan menjelaskan alat } \\
\text { dan bahan berkebun sekolah }\end{array}$ \\
Guru membagi siswa dalam empat kelompok \\
dan menugaskan kepada tiap kelompok untuk \\
menanam dan merawat tanaman \\
Guru bertanya jawab dengan siswa tentang \\
pembelajaran yang sudah dipelajari
\end{tabular}




\section{MIS Misbahul Islam}

Media tanam sedang masa pembenihan ulang dikarenakan tanaman sebelumnya mengalami kegagalan karena kekurangan air dan kurang terawatt saat libur sekolah. Menanggapi hal itu Kepala sekolah memindahkan kebun sekolah ke lahan yang berdekatan dengan rumah Kepala sekolah agar lebih terjaga dan mundah mendapatkan air untyuk menyiram. Jarak dengan sekolah tidak terlalu jauh jadi siswa masih bisa ikut serta merawat tanaman. Bibit yang ditanam adalah kankung,causin,tomat,cabe dan terong.

Dari hasil rekap penilaian sikap siswa yang dilaksanakan guru yakni: 1). Mulai terlihat, adalah sikap bertanggung jawab.2) Mulai berkembang, menghargai, disiplin, cinta tanaman dan lingkungan, kesabaran, kepedulian, kesabaran, berjiwa sosial dan semangat entrepreneur. 3) Membudaya, adalah sikap, kerjasama, mensyukuri nikmat Allah. Berikut tahapan proses pembelajaran yang dilaksanakan guru selama proses pembelajaran.

\section{Tabel 4. Tahapan Pembelajaran MIS Misbahul} Islam

\begin{tabular}{|c|c|}
\hline No & MIS Misbahul Islam \\
\hline 1. & $\begin{array}{l}\text { Memberikan salam dan berdoa, kemudian } \\
\text { membaca surat pendek bersama-sama dengan } \\
\text { siswa }\end{array}$ \\
\hline 2. & Guru mengecek absensi dan kehadiran siswa \\
\hline 3. & $\begin{array}{l}\text { Menginformasikan tema yang akan diajarkan } \\
\text { yaitu "peduli terhadap makhluk hidup" }\end{array}$ \\
\hline 4. & $\begin{array}{l}\text { Guru bertanya jawab dengan siswa tentang } \\
\text { materi yang akan dipelajari }\end{array}$ \\
\hline 5. & $\begin{array}{l}\text { Guru membagi siswa dalam } 3 \text { kelompok, } \\
\text { kemudian menyuruh siswa menuju kebun } \\
\text { sekolah kemudian guru menjelaskan jenis-jenis } \\
\text { alat dan bahan berkebun sekolah }\end{array}$ \\
\hline 6. & $\begin{array}{l}\text { Guru bertanya kepada siswa mengenai materi } \\
\text { yang telah dipelajari }\end{array}$ \\
\hline 7. & $\begin{array}{l}\text { Guru mengevaluasi siswa, kemudian menutup } \\
\text { pembelajaran }\end{array}$ \\
\hline
\end{tabular}

\section{PEMBAHASAN}

Berdasarkan hasil observasi dalam proses kegiatan belajar mengajar maka diperoleh hasil penelitian sebagai berikut. Pertama, peran perguruan tinggi dalam meningkatkan kompetensi pedagogik adalah sebagai fasilitator dalam mensosialisasikan model pembelajaran kebun sekolah melalui work- shop pembelajaran dan medampingi guru dalam menyusun perangkat pembelajaran dan melatih keterampilan dalam mengajar mulai dari kegiatan membuka hingga menutup pembelajaran. Hal ini sesuai dengan Undang-undang Nomor 12 Tahun 2012 Pasal 1 Ayat 9 bahwa dosen harus melaksanakan Tri Dharma Perguruan TInggi yaitu melaksanakan kegiatan pendidikan, penelitian, pengabdian dan pembinaan kompetensi guru sebagai upaya mencerdaskan bangsa. Selain itu PP Nomor 19 Tahun 2005 tentang standar pendidikan nasional bahwa tenaga kependidikan harus memiliki kompetensi pedagogik yang meliputi (1) pemahaman guru terhadap siswa, (2) perancangan dan pelaksanaan pembelajaran, (3) evaluasi hasil belajar, dan (4) pengembangan siswa untuk mengaktualisasi berbagai potensi yang dimilikinya.

Kedua, kompetensi pedagogik guru semakin terlatih dalam malaksanakan perencanaan pembelajaran, pelaksanaan dan evaluasi. Guru harus bisa mengatur jadwal kegiatan kebun sekolah dan menyusun RPP serta bahan ajar dengan membuat skenario pembelajaran, membuat lembar evaluasi, serta lembar observasi penilaian sikap siswa sehingga dapat terlihat sejauh mana pencapaian pembelajaran dan nilai-nilai karakter posrif yang muncul. Hal sesuai dengan penjelasan Fathurrohman ( 2007:13) bahwa kegiatan belajar mengajar hendaknya mengandung komponen yang terdiri dari tujuan, bahan ajar, kegiatan pelajaran, kegiatan belajar mengajar, metode, alat dan sumber serta evaluasi.

Ketiga, kebun sekolah dimanfaatkan guru sebagai laboratorium alami atau media pembelajaran berbasis lingkungan di berbagai mata pelajaran yang relevan. Hal ini sesuai dengan pernyataan Marheni (2017) bahwa pemanfaatan kebun sekolah membuat pembelajaran lebih bermakna karena siswa dilibatkan secara langsung sehingga siswa dapat mengkontruksi pengetahuannya sendiri. Kebun sekolah dapat dimanfaatkan sebagai laboratorium alami dalam pembelajaran IPA salah satunya untuk dapat meningkatkan pengetahuan siswa tentang nama ilmiah tumbuhan.

Keempat, melalui kegiatan berkebun guru dapat menggali nilai-nilai perilaku positif bagi siswa. Nilai tersebut menurut Hakam (2007:100) merupakan standar kelakuan, keindahan, efisiensi atau kebermaknaan yang seseorang dukung dan pertahankan. Nilai tersebut diantaranya meningkatkan rasa syukur terhadap sang pencipta, saling kerja sama, 
peduli terhadap lingkungan, dan membudayakan nilai kesabaran dan kerja keras. Kelima, pemanfaatan kebun sekolah dapat meningkatkan kecerdasan naturalistik bagi siswa. Siswa dapat berinteraksi langsung dengan alam dan memahami cara bertanam serta jenis-jenis tumbuhan. Hal ini menunjukan betapa pentingnya pengaruh alam terhadap perkembangan siswa.

Keenam, guru dapat meningkatkan kecintaan siswa untuk makan sayuran atau buah-buahan. Melalui pemanfaatan kebun sekolah, siswa lebih memahami berbagai jenis makanan dan pola makan yang sehat untuk diterapkan. Hal ini bahwa para siswa mampu memberikan pengaruh terhadap pola makan keluarganya juga, yaitu dengan membiasakan pola makan yang sehat di rumah. Ketujuh, kebun sekolah bisa dinikmati hasilnya untuk kebutuhan bersama dan bisa dijadikan media belajar kegiatan jual beli hasil pertanian dan berbagi (sosial). Jual beli merupakan salah satu contoh kegiatan entrepreneur atau wirausaha yang mencakup empat unsur penting yaitu daya pikir (kognitif), keterampilan (psikomotorik), sikap mental (afektif) dan kewaspadaan atau intuisi (Yusanto \& Karebet, 2002: 33). Delapan, pembelajaran kebun sekolah sebagai kegiatan relaksasi yang dapat mengurangi stress karena pancaindra ketika berkontaminasi dengan tumbuhan hijau akan memberi kesejukan dan kenyamanan antara siswa dan guru selama proses pembelajaran di sekolah.

Sembilan, memberikan waktu yang berkualitas bagi guru dan siswa dalam kebersamaan dan mendidik siswa untuk lebih menghargai tanaman, petani dan makanan. Sepuluh, proses belajar mengajar lebih bermakna karena siswa bukan hanya paham secara teori langkah bercocok tanam dan cara merawat tanaman, tapi peserta didik praktik secara langsung. Guru memberikan contoh secara langsung dengan menggunakan alat bahan dan lokasi kebun sekolah yang sudah disiapkan dan memberikan teladan kepada siswa untuk peduli tanaman dengan cara merawatnya. Hal ini sesuai dengan pernyataan Cheung dalam Fathurrahman (2007:7) bahwa mendidik bukan sekedar nasihat, karena menjadi sukses adalah memberikan contoh dengan perbuatan yang baik sesuai apa yang dikatakannya.

\section{SIMPULAN}

Lingkungan alam menjadi media pembelajaran yang dapat meningkatkan kompetensi mengajar guru dalam mengembangkan kreativitas dan kemandirian mendidik serta membudayakan siswa untuk mencintai lingkungan sekitar. Siswa dibiasakan untuk senang bercocok tanam sejak kecil dan guru dapat menjadikan kebun sekolah sebagai laboratorium alami atau media pembelajaran berbasis lingkungan di berbagai mata pelajaran yang relevan. Kebun sekolah juga bisa dinikmati hasilnya untuk kebutuhan bersama siswa dan guru. Selain dapat meningkatkan kecerdasan naturalistik siswa, terdapat nilai-nilai positif yang dapat digali oleh guru melalui kegiatan berkebun diantaranya (1) meningkatkan rasa syukur terhadap sang pencipta, sebagai kegiatan relaksasi yang dapat mengurangi stres; (2) memberikan waktu yang berkualitas bagi guru dan siswa dalam kebersamaan; (3) membudayakan nilai keabaran dan kerja keras; (4) mendidik siswa untuk lebih menghargai tanaman, petani dan makanan; (5) meningkatkan kecintaan makan sayur mayur atau buahan; serta (6) saling kerja sama dan peduli terhadap lingkungan.

\section{DAFTAR PUSTAKA}

Fathurrahman, Pupuh. Strategi Belajar Mengajar. Bandung: PT Rafika Aditama.

Hakam, Kamal Abdul. 2007. Pengantar Pendidikan Nilai. Bandung: CV Yasindo Multi Aspek.

Marheni. 2017. Pembelajaran Sains Tumbuhan Berbasis Etnobotani Terintegrasi Tanaman Obat. Jurnal Suluh Pendidikan, 15(2), 169175.

Nuryanto, M. Agus. 2017. Kritik Budaya Akademik di Pendidikan Tinggi. The Journal of Society \& Media, 1(1), 35-42.

Sadulloh, Uyoh. 2007. Pedagogik. Bandung: Cipta Utama.

Sangit. 2011. Analisis Data Kualitatif. (Online). Diakses pada http//:sangit26.blogspot.com.

Siraj-Baltchford, J., Smith, KC., \& Samuelsson, I.P. 2010. Education For Sustainable Development In The Early Years. Copenhagen: WHO Regional Office for Europa.

Sugiyono. 2007. Metode Penilaian Pendidikan (Pendekatan Kuantitatif, Kualitatif dan R/D). Bandung: Alfabeta.

Sukmadinata, N.S. 2010. Metode Penelitian Pendidikan. Bandung: PT Remaja Rosda Karya.

Wayan, Ekayanti N I. 2018. Kebun Sekolah sebagai Laboratorium Alami untuk Pembelajaran 
IPA: Mengenalkan Nama Ilmiah Tanaman Dalam Kehidupan Sehari-hari. Jurnal Suluh Pendidikan, 16(1), 51-55.

Yusanto, Muhammad., \& Karebet, Ismail. 2002. Menggagas Bisnis Islami. Jakarta: Gema Insani Press. 